\title{
The complete nucleotide sequence of the growth-hormone gene from the common carp (Cyprinus carpio)
}

\author{
Chien-Shun Chiou ${ }^{1}$, Huang-Tsu Chen ${ }^{1}$ and Wen-Chang Chang ${ }^{1,2}$ \\ 'Institute of Biological Chemistry, Academia Sinica, and ${ }^{2}$ Institute of Biochemical Science, National Taiwan University, Taipei \\ (Taiwan, China)
}

(Received 18 June 1990)

Key words: Growth hormone; Genomic sequence; Intron; Exon; (Carp); (C. carpio)

We have isolated and sequenced a phage clone from a common carp (Cyprinus carpio) genomic library that carries a gene encoding growth hormone (GH). This gene consists of five exons and four introns spanning a region of about 3 kilobasepairs. Its exons correspond with one of two reported cDNAs of carp $G H$ except for nine differences in the nucleotide sequence, while the encoded amino-acid sequences are identical. The sequence upstream from the transcription start point contains two tandem repeats of AACTCTCATG (from -85 to -62 ) and the typical TATA box. All the introns start with a consensus GT dinucleotide and end with AG. The arrangement of exons and introns is very similar to that seen in mammalian GH, but quite different from the $G H$ genes of rainbow trout and Atlantic salmon.

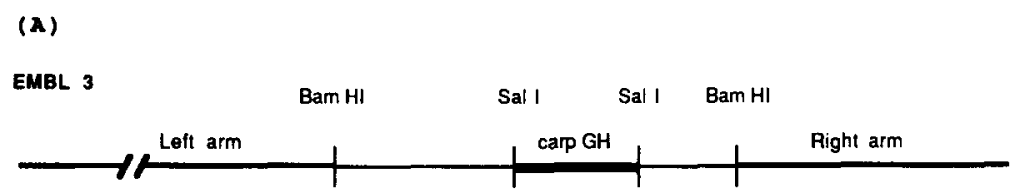

(B)

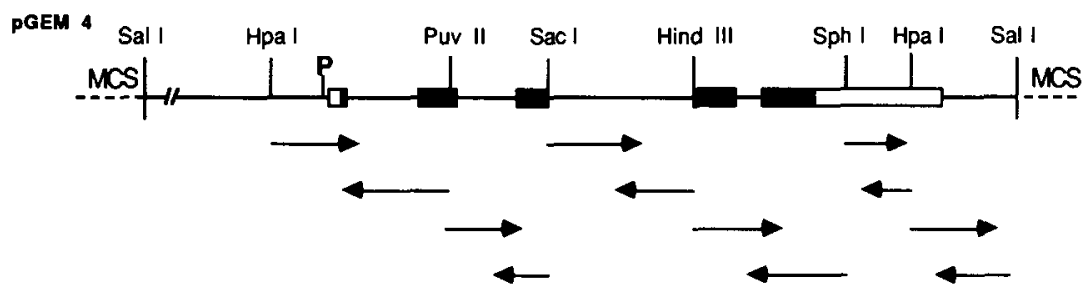

Fig. 1. The restriction map of the carp GH gene in EMBL 3 (A) and the sequencing strategy for the subcloned fragment in pGEM4 (B). Arrows indicate sequencing by the chain-termination method. P TATA box; MCS multiple cloning site; open box untranslated region; solid box coding region; the lines between the boxes indicate introns.

Growth hormones $(\mathrm{GH})$ are secreted by the pituitary glands of vertebrate species and are essential for normal growth and development of pre-adult. The genes encoding GH have been studied extensively in many species.

\footnotetext{
Abbreviations: $\mathbf{G H}$, growth hormone; kb, kilobasepairs.

The sequence data in this paper have been submitted to the EMBL/Genbank Data Libraries under the accession number X51969.

Correspondence: W.C. Chang, Institute of Biological Chemistry, Academia Sinica, P.O. Box 23-106, Taipei, Taiwan, China.
}

Nucleotide sequences have been determined for $G H$ genes from human [1,2], rat [3,4], porcine [5], bovine [6], ovine [7], rainbow trout [8] and Atlantic salmon [9]. Recently two cDNAs for carp $G H$ have been reported $[10,11]$ which show almost identical sequences in the coding region and remarkable differences in the $3^{\prime}$-untranslated region. Apparently, at least two genes encoding GH must exist in the carp. This report describes the cloning and characterization of a carp $G H$ gene corresponding to one of the two reported cDNAs.

Genomic DNA was prepared from carp eggs and partially digested with BamHI. Fragments of $10-20$ 
kilobasepairs $(\mathrm{kb})$ were recovered from $0.5 \%$ agarose gel and cloned into lambda phage EMBL 3. Procedures from the commercial supplier (Promega Inc.) were followed for in vitro packaging and transfection.

The genomic library was screened using nick-translated ${ }^{32}$-labeled carp GH cDNA [10] as a probe. The positive clones were further analyzed by repeated hybridization with the probe and the positive fragments were subcloned into plasmid pGEM4. The recombinant phage and plasmid DNA were purified according to standard procedures $[12,13]$. The DNA sequence was determined using a chain-termination procedure [14] with denatured plasmid templates [15].

The transcription start site was determined by primer extension using carp pituitary mRNA as template. About $2 \mu \mathrm{g}$ of mRNA prepared as previously described

gttaacttagtgccaacatcatcccagag catggaaatagccatacacataaatgaccggaaccgctacactggt tcgtatggtgtctaaatac acgcagcaatgcataatcaacatagttctcatgga actctcatgttcaactctcatg cattaagatgcattaaacatgttcatgccaca $+1$

Fig. 2. The complete nucleotide sequence of the carp $G H$ gene. Exons are shown by capitals and introns by lower-case letters. The numbering is given in the right margin and begins at the cap site $(+1)$. Encoded amino-acid residues are represented by one-letter codes above the codons. Asterisks indicate the positions at which the bases in mRNA [11] are different as shown below the genomic sequence; hyphens indicate deletions. 
[10] was annealed to 1 pmol of a synthetic primer: CGCTCAGGGTAGACAAACTC which is complementary to the genomic sequence from nucleotides 54 35 (Fig. 2). The primer extension reaction was carried out with the mouse Moloney leukemia virus reverse transcriptase. The ${ }^{32}$-labeled reaction products were analyzed by electrophoresis in $10 \%$ polyacrylamide sequencing gel.

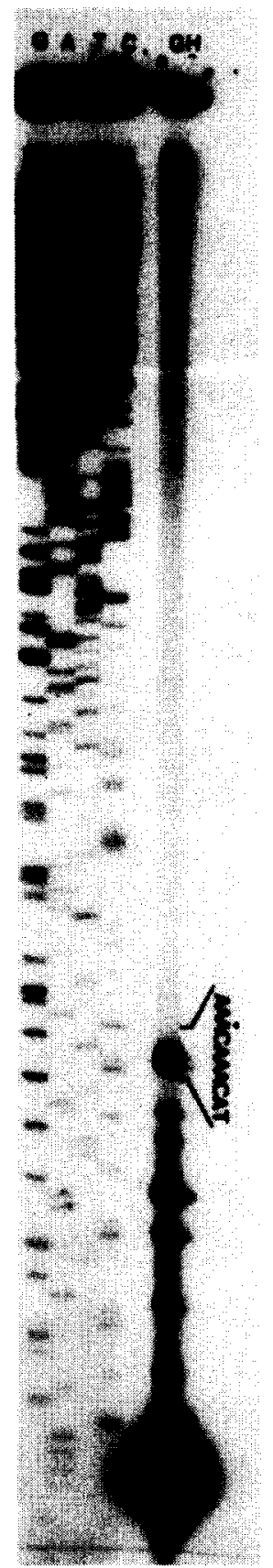

Fig. 3. Determination of the transcription start site. Lanes $G, A, T$ and $C$ : size markers from dideoxy sequencing reaction products of vector mp18 as template with a suitable primer. Lane GH: primer-extension products generated using synthetic oligonucleotide primer and mRNA. The adenine residue corresponding to the 5 ' end of carp GH mRNA is indicated by an asterisk.

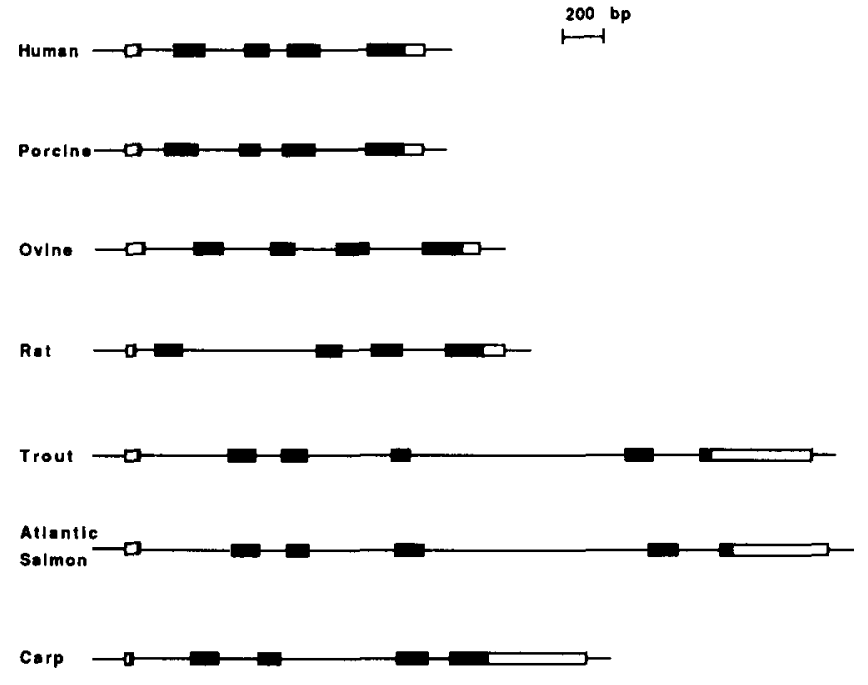

Fig. 4. Comparison of the $G H$ structure of human [1,2], porcine [5], ovine [7], rat [3,4], trout [8] salmon [9] and carp (this study). Open box, untranslated region; solid box, coding region; lines between exons, introns.

Of the $1.5 \cdot 10^{6}$ recombinant plaques screened, two clones hybridized strongly with the ${ }^{32} \mathrm{P}$-labeled cDNA probe. Restriction analysis of the DNA showed that they carried the same $G H$ gene in opposite orientation (data not shown). Both clones contained an inserted 15 kb DNA fragment. The exon-containing region was narrowed down further to a $4.3 \mathrm{~kb}$ fragment produced by SalI digestion. This fragment was subcloned into pGEM 4 and sequenced (Figs. 1 and 2).

The transcription start site was determined by the primer extension method (Fig. 3) and was found to be an adenine residue (Fig. 2). As is often the case, the primer extension also produced some shorter oligonucleotides, probably due to the dissociation of reverse transcriptase caused by RNA secondary structures. The primary transcript is 2364 nucleotide long, with the transcription start site located at almost the same position as the $G H$ of rainbow trout [8] and Atlantic salmon [9]. The sequence upstream from the transcription start point contains two tandem repeats of a decanucleotide AACTCTCATG (from -85 to -62 ) and a typical TATA box at -28 (Fig. 2). All introns start with a GT dinucleotide and end with an AG, analogous to other reported splice sequences [16]. The carp $G H$ gene consists of five exons and four introns spanning a region of about $3 \mathrm{~kb}$. It is interesting that the arrangement of exons and introns in this gene is more similar to that of mammalian $G H$ s than that of the other two fish genes (Fig. 4), which are much longer in sequence and have one more intron and exon. Comparison between the nucleotide sequences of the exon regions and the cDNAs $[10,11]$ reveals that this genomic clone corresponds almost perfectly to the cDNA reported by Koren et al. [11] with only nine differences in the nucleotide se- 
quence, while the encoded amino-acid sequences are identical (Fig. 2).

This genomic clone is certainly not that which would give rise to the mRNA described in our previous report [10], as the genomic sequence is quite different from the mRNA immediately after the translation stop codon down to the end of the last exon. The gene corresponding to our reported cDNA [10] still awaits further screening and characterization.

This study was financially supported by a grant from the National Science Council of the Republic of China.

\section{Reference}

1 DeNoto, F.M., Moore, D.D. and Goodman, H.M. (1981) Nucleic Acids Res. 9, 3719-3730.

2 Seeburg, P.H. (1982) DNA 1, 239-249.

3 Barta, A., Richards, R.I., Baxter, J.D. and Shine, J. (1981) Proc. Natl. Acad. Sci. USA 78, 4867-4871.

4 Page, G.S., Smith, S. and Goodman, H.M. (1981) Nucleic Acids Res. 9, 2087-2104.
5 Vize, P.D. and Wells, J.R.E. (1987) Gene 55, 339-344.

6 Woychik, R.P., Camper, S.A., Lyons, R.H., Horowitz, S., Goodwin, E.C. and Rottman, F.M. (1982) Nucleic Acids Res. 10, 7197-7210.

7 Orian, J.M., Mahoncy, J.V.O. and Brandon, M.R. (1988) Nucleic Acids Res. 16, 9046.

8 Agellon, L.B., Davies, S.L., Chen, T.T. and Powers, D.A. (1988) Proc. Natl. Acad. Sci. USA 85, 5136-5140.

9 Johansen, B., Johansen, O.C. and Valla, S. (1989) Gene 77, 317324.

10 Chao, S.C., Pan, F.M. and Chang, W.C. (1989) Biochim. Biophys. Acta $1007,233-236$.

11 Koren, Y., Sarid, S., Ber, R. and Daniel, V. (1989) Gene 77, 309-315.

12 Maniatis, T., Fritsch, E.F. and Sambrook, J. (1982) Molecular Cloning, A Laboratory Manual. Cold Spring Harbor Laboratory, Cold Spring Harbor, New York.

13 Birnboim, H.C. and Doly, J. (1979) Nucleic Acids Res. 7, 15131517.

14 Sanger, F., Nicklen, S. and Coulson, A.R. (1977) Proc. Natl. Acad. Sci. USA 74, 5463-5467.

15 Hattori, M. and Sakaki, Y. (1986) Anal. Biochem. 152, 232-238.

16 Breathnach, R., Benoist, C., O'Hare, K., Gannon, F. and Chambon, P. (1978) Proc. Natl. Acad. Sci. USA 75, 4853-4857. 